\title{
ENFERMEIRAS NA ATENÇÃO BÁSICA: ENTRE A SATISFAÇÃO E A INSATISFAÇÃO NO TRABALHO
}

\author{
NURSES IN BASIC CARE: BETWEEN JOB SATISFACTION AND DISSATISFACTION \\ ENFERMERAS EN LA ATENCIÓN BÁSICA: ENTRE LA SATISFACCIÓN \\ Y LA INSATISFACCIÓN EN EL TRABAJO
}

\author{
Elaine Cristina Novatzki Forte ${ }^{1}$ \\ Denise Elvira Pires de Pires ${ }^{2}$
}

Resumo Trata-se de uma pesquisa qualitativa, com o objetivo de analisar os motivos de satisfação e insatisfação no trabalho, segundo os modelos assistenciais utilizados na atenção básica no Brasil: o tradicional e a Estratégia Saúde da Família. Foram entrevistadas vinte enfermeiras em Florianópolis, Santa Catarina. Os dados foram coletados entre março e maio de 2013, por meio da triangulação, entrevistas e observação, organizados no software Atlas.ti e examinados com base na análise de conteúdo. O estudo mostrou 25 diferentes motivos de satisfação e 23 diferentes motivos de insatisfação no trabalho. Não houve diferenças marcantes entre os dois modelos de atenção, e essas têm maior relação com a gestão municipal e com as condições de trabalho.

Palavras-chave satisfação no trabalho; atenção primária à saúde; saúde da família; papel da enfermeira.
Abstract This is a qualitative study aimed at analyzing the reasons for job satisfaction and dissatisfaction, as reported by twenty nurses who work in two care models used in basic care in Brazil: The traditional model and the Family Health Strategy. Data were collected between March and May 2013, through triangulation, interviews, and observation; they were organized in the Atlas.ti software and examined based on content analysis. The study showed 25 different reasons for job satisfaction, and 23 different reasons for job dissatisfaction. There was no significant differentiation between the two care models, indicating that they are more related with municipal management and work conditions.

Keywords job satisfaction; primary health care; family health; role of the nurse. 


\section{Introdução}

Com o surgimento do Sistema Único de Saúde (SUS), no final da década de 1980 no Brasil, é demandada dos serviços públicos de saúde uma mudança significativa no modelo assistencial. Em 1994, o Programa Saúde da Família (PSF) surge como uma iniciativa que sinaliza para a construção de um modelo assistencial que considere o processo saúde/doença em sua totalidade em uma perspectiva individual e coletiva. Em 1998, o PSF consolida-se como Estratégia Saúde da Família (ESF) visando reorientar as práticas em saúde no âmbito da atenção básica, denominação brasileira para Atenção Primária em Saúde (APS) (Brasil, 2012).

No entanto, na atenção básica, coexistem, ainda, dois modelos assistenciais: o modelo tradicional, baseado na ciência cartesiana (Atenção Básica Tradicional - ABT) e o modelo da ESF, que visa à atenção integral às necessidades dos indivíduos na família e na comunidade.

$\mathrm{Na}$ atenção básica a enfermeira, além do técnico/a ou auxiliar de enfermagem, estão presentes nos dois modelos de atenção e fazem parte da equipe mínima prescrita pelo Ministério da Saúde para a ESF. Essa presença, importância numérica e características do trabalho da enfermagem fazem com que a qualidade das suas ações influencie diretamente a qualidade da assistência em saúde (Pires, 2009).

O trabalho das enfermeiras, pelas suas características de cuidar de pessoas em situação de adoecimento e de promoção da saúde, por envolver um trabalho coletivo e de relação entre pessoas, e por incorporar a complexidade das dimensões de cuidar, administrativo/gerencial e educativa, por vezes é desgastante e gerador de insatisfação. O reconhecimento da complexidade e a importância desse trabalho e de situações que provocam insatisfação no seu exercício têm gerado diversos estudos, os quais identificam, dentre os fatores de insatisfação: jornada de trabalho extenuante, aumento das cargas de trabalho, falta de autonomia, não participação no processo decisório da gestão dos serviços, exposição a riscos biológicos e ocupacionais em geral e salários muito aquém do almejado (Pires et al., 2013; Trindade et al., 2010).

A satisfação no trabalho é entendida como um estado emocional de prazer resultante da relação entre o indivíduo e seu trabalho e a insatisfação tem o sentido inverso, em que residem a frustração e a negação dos valores relacionados às suas atividades laborais, configurando situações opostas de um mesmo fenômeno. Um modo de analisar essa relação é dada pela Psicodinâmica do Trabalho, que visa compreender as influências da organização das atividades laborais sobre a saúde do trabalhador, em especial em relação ao sofrimento psíquico. Essa maneira de analisar a relação entre saúde e trabalho busca compreender como os trabalhadores conseguem sustentar a estabilidade psíquica, apesar das condições de desgastantes, em que, muitas vezes, se encontram. O sofrimento gerado pelo 
trabalho é decorrente do confronto entre a subjetividade do trabalhador e as condições, as relações e a organização do trabalho, em especial, pela influência do modo de produção capitalista (Merlo e Mendes, 2009).

A satisfação no trabalho tem sido associada à saúde do trabalhador, pelo fato de que indivíduos mais satisfeitos apresentam melhor qualidade de vida e menores índices de adoecimento físico e mental. Insatisfação e sofrimento psíquico influenciam diretamente no comportamento do trabalhador, o que se traduz na forma de absenteísmo, rotatividade, acidentes de trabalho, greves, dentre outros (Fernandes et al., 2010).

O referencial teórico deste estudo está ancorado na teoria sociológica sobre Processo de Trabalho, na abordagem de Dejours acerca da relação entre prazer e sofrimento no trabalho e na Política Nacional de Atenção Básica (PNAB) vigente no Brasil desde 2006. Por considerar o papel fundamental exercido pelas enfermeiras que compõem as equipes de saúde na atenção básica, o objetivo deste estudo é analisar os motivos de satisfação e insatisfação no trabalho, relatados por enfermeiras que atuam em dois modelos assistenciais utilizados na atenção básica no Brasil - o modelo tradicional (ABT) e a Estratégia Saúde da Família (ESF).

\section{Metodologia}

Pesquisa de abordagem qualitativa ${ }^{3}$ realizada em Unidades Básicas de Saúde (UBSs) de quatro municípios da região da grande Florianópolis, Santa Catarina, Brasil. Os municípios foram selecionados intencionalmente, para definir uma amostra composta por UBSs que atuam apenas no modelo da ESF ou no modelo da ABT, incluindo as UBSs indicadas pela Secretaria de Saúde dos municípios, por serem exemplo exitoso no modelo de organização proposto. As enfermeiras entrevistadas foram selecionadas intencionalmente, totalizando vinte: dez da ABT e dez da ESF, representando igualdade numérica dos dois modelos. Foram aplicados, ainda, os seguintes critérios de inclusão: enfermeiras com mais de um ano de experiência na atenção básica e que estavam em atividade no momento da coleta de dados. Foram excluídas as enfermeiras afastadas do trabalho por motivos de licença de saúde (duas enfermeiras).

Para a coleta de dados foi utilizada a triangulação de técnicas: entrevista semiestruturada e observação. O conteúdo da entrevista consistiu na maneira como o trabalho em cada modelo assistencial influencia o trabalho profissional; aspectos do trabalho em cada modelo assistencial que dificultam o trabalho como enfermeira; contribuições do modelo assistencial para um trabalho mais satisfatório; relação do modelo com a satisfação no trabalho; e, por fim, citação de três principais motivos de satisfação e de insatisfação no trabalho. $\mathrm{O}$ roteiro de observação foi composto de aspectos do trabalho das enfermeiras relacionados à clientela, à chefia e aos colegas da equipe. 
Todas as participantes assinaram o termo de consentimento livre e esclarecido, seguindo as normas da resolução n. 466/12 que versa sobre as diretrizes e normas regulamentadoras de pesquisas que envolvem seres humanos. Para garantir o anonimato das participantes, elas foram identificadas pela letra $\mathrm{E}$ de enfermeira, seguida da letra que se refere aos modelos assistenciais (E para ESF e $\mathrm{T}$ para modelo tradicional) e, por último, do número cardinal na ordem em que aconteceram as entrevistas. Do mesmo modo, os municípios foram identificados pelas primeiras letras do alfabeto. As observações foram abreviadas pela sigla OBS, seguida do modelo (ABT ou ESF) e um número cardinal na ordem em que foram realizadas. A coleta de dados foi realizada no período de fevereiro a março de 2013 e as entrevistas e observações, gravadas e transcritas pela pesquisadora. Os dados foram organizados e codificados com auxílio do software para análise de qualitativos, o Atlas.ti 7.0 (Qualitative Research and Solutions), seguindo a proposta de análise de conteúdo temática (Bardin, 2009). No primeiro momento, fez-se a leitura flutuante das entrevistas e observações transcritas, gerando impressões iniciais, concomitantemente à organização dos dados no software. No segundo momento, realizou-se a codificação das informações contidas no conjunto dos documentos (entrevistas e notas de observação) em busca de núcleos de sentido em cada documento, mediante a seleção de recortes e classificação em categorias temáticas. Por fim, a análise foi concluída com a elaboração das macro categorias temáticas conforme os objetivos do estudo, sob o olhar do referencial teórico adotado.

Todos os preceitos éticos foram respeitados e a pesquisa teve parecer emitido pelo Comitê de Ética em Pesquisa da Universidade Federal de Santa Catarina (UFSC), sob n. 207.307.

\section{Resultados}

\section{Motivos de satisfação encontrados}

Os motivos de satisfação no trabalho das enfermeiras da atenção básica, em ambos os modelos de atenção estão dispostos na Figura 1.

\section{Motivos de satisfação na ABT}

No modelo das unidades básicas tradicionais prevalece o atendimento à população guiado pela demanda espontânea e o atendimento por programas (tuberculose, hipertensão, imunizações, saúde da mulher e outros), e na organização é evidente a hegemonia do modelo centrado nos procedimentos e no atendimento curativo.

Considerando os motivos de satisfação no trabalho na ABT, foram mencionados 15 motivos de satisfação, conforme mostrado na Figura 1. Entretanto, 


\section{Figura 1}

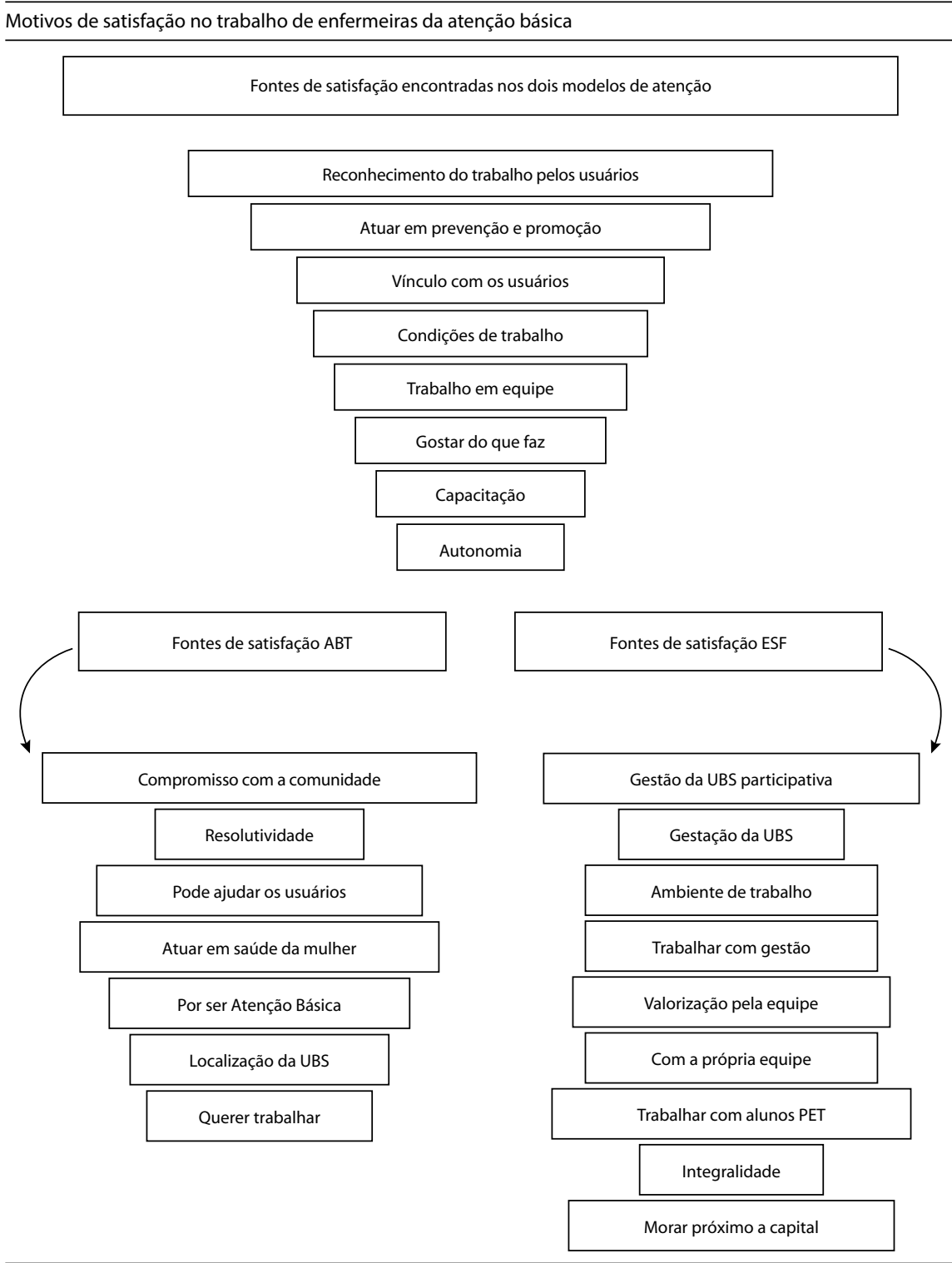

Nota

ABT: Atenção Básica Tradicional; ESF: Estratégia Saúde da Família; PET:Programa de Educação pelo Trabalho; UBS: unidade básica de saúde.

os três de maior destaque foram: $1^{\circ}$ ) Trabalho em equipe; $2^{\circ}$ ) Vínculo com a comunidade e $3^{\circ}$ ) Reconhecimento por parte dos usuários e o gostar do que faz.

O principal motivo de satisfação no trabalho relatado pelas enfermeiras na $\mathrm{ABT}$ é o trabalho em equipe, relatado por sete das dez participantes da pesquisa.

(...) esse trabalho em equipe multiprofissional que eu acho que é muito importante (ET8). 
(...) pelo trabalho em equipe e pela minha equipe que é maravilhosa (ET6).

O vínculo com a comunidade, com os usuários, aparece como segundo fator mais importante de satisfação, mencionado por seis enfermeiras.

(...) esse vínculo com a comunidade, de poder acompanhar, acompanhar o crescimento das crianças (...) (ET6).

Esse vínculo, quando eles chegam e sabem meu nome, parece ridículo assim, mas é bem importante, me dá prazer mesmo, saber que eles dependem da gente (ET10).

Em terceiro lugar, aparecem como motivos de satisfação o reconhecimento por parte dos usuários e o gostar do que faz, ambos mencionados por quatro participantes.

(...) pelo reconhecimento dos pacientes, às vezes eles retornam só pra contar pra gente que deu certo (ET10).

(...) por gostar do que eu faço (ET5).

\section{Motivos de satisfação na ESF}

'Gostar do que faz' surge como principal motivo de satisfação no trabalho na ESF, relatado por seis das entrevistadas.

(...) eu gosto do que eu faço, eu sou satisfeita com o que eu proporciono para os pacientes (EE4).

(...) eu amo o que eu faço, eu gosto de dar assistência para as pessoas, eu gosto de escutar, eu vou fundo nos meus casos, eu trato todo mundo com respeito, eu acho que é isso, eu amo o que eu faço (EE8).

Em segundo lugar, o 'trabalho em equipe e o reconhecimento' por parte dos usuários também se destacam como motivos de satisfação pelas enfermeiras da ESF, mencionados por cinco delas.

Acho que é isso, a ESF prevê o trabalho em equipe, e o enfermeiro quando trabalha junto com o médico, ele consegue realizar as ações de cuidado de forma mais eficiente, o trabalho em equipe é o grande facilitador (EE5).

(...) o trabalho em equipe, a gente passa mais tempo com os colegas de trabalho do que com a própria família (EE10). 
O reconhecimento da comunidade é um, porque ele vem no centro de saúde, a própria comunidade chega pedindo por tal pessoa, eles sabem que a gente resolve (EE2).

Há uma boa interação entre os membros da equipe, parecem tomar as atitudes em conjunto, o que fortalece as suas ações. As reuniões de equipe são semanais, e nelas são realizados os planejamentos, as trocas de informações e todos os procedimentos são realizados após o parecer do conjunto da equipe (OBS ESF 3).

Em terceiro lugar, com a mesma frequência, mencionados por quatro entrevistadas, apareceram o salário, o modelo de gestão participativa na UBS e o vínculo estabelecido com os usuários.

(...) o salário, a gente ganha um salário que em parte satisfaz as nossas necessidades (EE9).

A nossa gestão é assim, tem um colegiado gestor que é um representante de cada equipe de saúde, não precisa ser sempre a mesma pessoa, então nós somos seis equipes, a gente tem reuniões quinzenais em cada reunião um membro da equipe tem que ir, o que está desconfortável ou [quando] o processo de trabalho tem que ser modificado, [quando há necessidade de] incorporar alguma tecnologia, alguma prática, alguma coisa a gente discute no colegiado e leva para as equipes (EE7).

(...) todo o planejamento envolve todos os profissionais, o que eles chamam de gestão compartilhada (OBS ESF 3).

(...) a relação com os pacientes, o vínculo, de poder fazer algo, essa troca me deixa satisfeita, estar sendo importante naquele momento (EE3).

\section{Motivos de insatisfação na atenção básica}

Os motivos de insatisfação no trabalho referidos pelas enfermeiras da atenção básica, na ABT e na ESF, estão dispostos na Figura 2.

\section{Motivos de insatisfação na ABT}

O principal motivo de insatisfação no trabalho relatado por seis enfermeiras da ABT é o salário. Os ganhos nesse modelo de atenção ficam muito aquém dos proventos da categoria no modelo da ESF, e isso causa insatisfação nessas profissionais que cumprem a mesma carga horária das que trabalham na ESF.

O salário, acho que a gente não é valorizada (...) (ET3). 
Figura 2

Motivos de insatisfação no trabalho de enfermeiras da atenção básica

Fontes de insatisfação encontradas nos dois modelos

\begin{tabular}{|c|}
\hline Falta de atendimento dos usuários \\
\hline Dificuldades com a gestão municipal \\
\hline Falta de recursos humanos \\
\hline Falta de recursos materiais \\
\hline Relações interpessoais \\
\hline Jornada de 40 horas \\
\hline Demanda excessiva \\
\hline Desvalorização \\
\hline Estrutura física \\
\hline Salário \\
\hline A
\end{tabular}

\begin{tabular}{|c|c|}
\hline Fontes de insatisfação na $\mathrm{ABT}$ & Fontes de insatisfação na ESF \\
\hline Horário de funcionamento da UBS & Falta autocuidado dos usuários \\
\hline Cultura centrada no médico & Não tem o foco da ESF \\
\hline Falta capacitação gestores & Prescrito diferente do real \\
\hline Por morar em outra cidade & Déficit referenciamento \\
\hline Supervisão dos ACS & Sobrecarga de trabalho gestores \\
\hline
\end{tabular}

Nota

ABT: Atenção Básica Tradicional; ESF: Estratégia Saúde da Família; UBS: unidade básica de saúde; ACS: agente comunitário de saúde.

(...) o salário, a diferença de um município para outro, aqui perto, é gritante (ET8).

O segundo motivo de insatisfação, citado por cinco enfermeiras, é a falta de estrutura física adequada. Essa problemática pode ser evidenciada, também, na observação. 
O que mais chama atenção nessa UBS é justamente essa proximidade com a Policlínica, que por um lado é bom, por outro é péssimo, pois o espaço físico fica limitado a seis portas de um corredor, e confunde os usuários quando é necessário marcar consulta com um especialista, e isso acaba deixando os enfermeiros insatisfeitos com essa situação (OBS ABT 1).

(...) as duas enfermeiras dividem uma sala, e a outra enfermeira, que é também coordenadora da unidade, fica numa sala de 1,5 metros quadrados (OBS ABT 3).

Como terceiro motivo de insatisfação, aparecem a falta de recursos humanos e materiais e o 'apadrinhamento político' mencionados por quatro das participantes desse modelo assistencial. No momento da pesquisa, todas as UBSs tradicionais estudadas tinham déficits no quadro de funcionários (principalmente, agentes comunitários de saúde e médicos), assim como déficits no estoque do almoxarifado (faltavam fraldas geriátricas, fitas de glicemia, dentre outros). Em todas as UBSs estudadas, as enfermeiras relataram a influência negativa do 'apadrinhamento político'. Este é entendido como uma forma de favorecimento aos usuários do serviço, por parte de pessoas que ocupam cargos no Poder Executivo e/ou Legislativo.

(...) a falta de material, agora, por exemplo, faz três meses que a gente não recebe fralda pra acamado, e é complicado, o paciente acha que eu é que não pedi (ET7).

(...) falta de pessoal é uma constante, principalmente de médicos e agentes comunitários de saúde, o que prejudica o atendimento e o cadastramento das famílias da comunidade, e isso nos sobrecarrega muito (ET1).

A parte da politicagem é muito forte aqui, quando eu entrei foi muito difícil. Eu me negava dar uma medicação, porque a pessoa tinha que passar pelo médico antes, eu orientava isso. Aí a pessoa ligava para o secretário municipal de saúde, e o secretário liberava, e eu me recuso a fazer isso; no começo, a gente foi muito mal vista, no começo eu sofri muito (...) tu passas por obstáculos muito fortes, alguns maiores que tu (ET5).

\section{Motivos de insatisfação na ESF}

A sobrecarga de trabalho e a demanda excessiva são uma constante no trabalho das enfermeiras da ESF. Sustentam essa afirmação seis dos relatos.

(...) sobrecarga de trabalho, a demanda é maior do que os recursos de pessoal (EE1).

(...) eu me sinto muito sobrecarregada (...) eu acumulo duas funções, e o paciente não entende que eu tenho que parar a assistência em algum momento para resol- 
ver as questões burocráticas, tenho muitas coisas acumuladas, não consigo dar conta de tudo (EE10).

Durante o período de observação, constatou-se a demanda excessiva de usuários em quatro das cinco UBSs estudadas. A sobrecarga de trabalho fica evidenciada ao presenciar as enfermeiras correndo o tempo todo e fazendo várias atividades ao mesmo tempo.

Uma das enfermeiras mostrou-se muito desanimada; além dos relatos dados em entrevista, ela demonstrou uma insatisfação muito grande, principalmente com a demanda espontânea que chega à UBS. O que mais chama atenção nessa UBS é o excesso de demanda, a unidade fica lotada todos os dias (OBS ESF 1).

O segundo motivo de insatisfação, citado por cinco enfermeiras, se refere à estrutura física inadequada.

(...) a nossa unidade tá muito precária, é muito pequena, e eu fico envergonhada de dizer que trabalho aqui; essa fachada é muito feia, tem infiltração e isso desmotiva, porque não tem condições de trabalho, a minha mesa é uma carteira de escola, a cadeira não tem apoio de braço, eu não consigo respirar direito aqui (EE10).

O 'apadrinhamento político' surge como terceiro motivo, este emergiu de forma mais discreta por parte das enfermeiras da ESF, entretanto, marca presença na lista das insatisfações dos profissionais.

(...) a questão política que permeia os profissionais de saúde da atenção básica, muitos mandos de vereadores, pessoas da comunidade que fazem pressão popular, tem que passar gente na frente, ter que dar predileções, a influência negativa que a política tem sobre o processo de trabalho aqui (EE9).

\section{Discussão}

O estudo mostrou 24 diferentes motivos de satisfação e 23 diferentes motivos de insatisfação no trabalho. Não observamos diferenciação dos motivos de satisfação das enfermeiras entre a ABT e a ESF. Os motivos parecem independentes do modelo assistencial, o que sinaliza que os motivos de satisfação das enfermeiras têm pouca relação com o modelo assistencial e maior relação com a organização do trabalho, com a gestão municipal e com as condições de trabalho.

O trabalho em equipe se destacou como principal motivo de satisfação no trabalho das enfermeiras na ABT e como segundo principal motivo na ESF. 
No entanto, trabalho em equipe, no caso da $\mathrm{ABT}$, parece ser compreendido como o trabalho realizado pela equipe de saúde, composta pelo médico, enfermeira, técnico e/ou auxiliar de enfermagem e pelos agentes comunitários de saúde. As enfermeiras sentem que o fato de existir uma equipe lhes proporciona segurança, neste caso aproxima-se da ideia de equipe agrupamento (Peduzzi et al., 2011). Na ESF, as enfermeiras descreveram o trabalho em equipe com características de colaboração e de trocas de diferentes olhares, o que proporciona uma forma mais eficaz de atenção à complexidade das necessidades dos usuários. Este tipo de equipe identifica-se com a perspectiva de atuação interdisciplinar e da equipe integração (Peduzzi et al., 2011). O trabalho em equipe na ESF envolve discussão dos casos e respeito com os colegas de outras profissões, o que facilita a resolutividade da assistência. Pela sua potencialidade de qualificação da assistência e de integração entre os agentes do trabalho, as abordagens interdisciplinares devem ser incentivadas pelos gestores dos serviços e pelos próprios profissionais (Finlayson e Raymont, 2012).

$\mathrm{O}$ trabalho em equipe envolve diferentes profissionais no processo de assistência. Cada uma das equipes é fator importante e fundamental para o sucesso da assistência em saúde. Ao desenvolver o trabalho coletivo da equipe, partilhando de ideias e propostas, o trabalho se torna cooperativo e beneficia usuários e trabalhadores.

Também se destacou, dentre os motivos de satisfação nos dois modelos, o reconhecimento pelo trabalho realizado e o vínculo com os usuários. Em relação ao reconhecimento, as falas das participantes mostram que as enfermeiras se esforçam para fazer o melhor, dispendem energia e amor pelo que fazem, justo então que se sintam satisfeitas quando o seu trabalho é reconhecido pelos usuários dos serviços, e este reconhecimento dos usuários se torna um fator determinante para a satisfação no trabalho, identificado pelas enfermeiras nos dois modelos assistenciais. Quando os trabalhadores não são reconhecidos, quando seus esforços passam despercebidos pelos outros, "isso acarreta em sofrimento perigoso para a saúde mental devido à desestabilização do referencial que apoia a identidade" (Dejours, 2011). O prazer no trabalho é influenciado pelo reconhecimento, pelo reconhecer-se naquilo que está fazendo (Marx, 1983; Cortella, 2009). Quando o trabalhador olha para o seu trabalho e não se percebe nele, não reconhece o trabalho como seu, executa tarefas delegadas e repetitivas e não tem controle sobre o processo de trabalho, gera insatisfação e alienação (Marx, 1983; Cortella, 2009; Gernet e Dejours, 2011). A satisfação no trabalho contribui para diminuir a rotatividade nos serviços, criando um ambiente propício para o estabelecimento do vínculo entre profissionais e usuários, bem como para o desenvolvimento da motivação.

Mesmo diante de condições que causam insatisfação no trabalho, as enfermeiras encontram motivos que as estimulam. O 'gostar do que faz' é mediado pela interação com os usuários e os colegas de trabalho. Quando questionadas 
sobre os motivos de satisfação no trabalho, as enfermeiras afirmaram que se identificam com o trabalho e com a possibilidade de interagir com os usuários.

Quanto ao vínculo com os usuários, cabe destacar que essa expressão designa uma tecnologia de relações que vem sendo mencionada na literatura e na política de saúde como desejável para que as práticas de cuidado se desenvolvam mais acolhedoras, ágeis e resolutivas (Brasil, 2012; Coelho e Jorge, 2009). Os profissionais da atenção básica devem se responsabilizar e interagir com a comunidade, gerando 'laços' mais estreitos com as famílias, a fim de favorecer as relações de participação e melhorar os resultados (Coelho e Jorge, 2009).

Os resultados da pesquisa mostraram que há reciprocidade nesse vínculo, assim como as profissionais enfermeiras identificam os usuários e conhecem suas histórias de vida, os usuários conhecem as enfermeiras da UBS responsáveis pelos seus cuidados, chamando-as pelo nome, caracterizando uma relação de confiança entre profissional e usuário do serviço, o que contribui para o sucesso da assistência em saúde.

Outro fator de satisfação, a gestão participativa, está prevista na PNAB (Brasil, 2012) e ocorre quando o conjunto dos trabalhadores é percebido como protagonista no processo de gestão, o que possibilita um fazer coletivo valorizando as pessoas como talentos que colaboram para o alcance de determinada missão. Estudo recente (Pires et al., 2013) analisou as influências das inovações tecnológicas nas cargas de trabalho dos profissionais de saúde. Constatou-se que, quando o modelo de gestão não é participativo, ou seja, quando os profissionais não participam do planejamento e do processo de tomada de decisões, ocorre aumento das cargas de trabalho, pois as decisões do que é prioridade, muitas vezes não refletem a real necessidade do cotidiano de trabalho.

Alguns dos motivos encontrados somente na ESF se justificam por serem específicos das unidades estudadas, como é o caso da gestão participativa, que foi encontrada em uma UBS, na qual o modelo de gestão é o compartilhado. O trabalho com alunos também é uma característica própria dessa UBS, que recebe alunos de graduação na modalidade Programa de Educação pelo Trabalho (PET-Saúde).

Dentre os principais motivos de insatisfação no trabalho, em ambos os modelos, as condições de trabalho tiveram importante destaque, incluindo: déficits na estrutura física e nos instrumentos de trabalho, salários deficitários e jornada de trabalho excessiva, excesso de demanda relacionada ao dimensionamento de pessoal e falta de educação continuada. As condições de trabalho, como déficits na estrutura física e nos recursos humanos e materiais, foram relatadas como motivos de insatisfação em estudos anteriores, assim como maiores índices de morbidade dos trabalhadores de enfermagem (Santana et al., 2013; Trindade e Pires, 2013).

No presente estudo, as UBSs do modelo tradicional estão sucateadas, há falta de manutenção nos prédios, isso quando existe UBS. Algumas enfer- 
meiras entrevistadas atendem a população em escolas abandonadas, utilizando carteiras escolares como mesa de consultório. Independente do modelo de atenção adotado pelo município, a falta de insumos materiais é frequente. Das vinte enfermeiras entrevistadas, 16 referiram esse fator, pois dificulta o trabalho cotidiano dos serviços e, principalmente, impossibilita o profissional de prestar uma assistência de qualidade, e o usuário sai prejudicado.

$\mathrm{O}$ adequado dimensionamento de pessoal de enfermagem é considerado um indicador essencial para garantir a humanização da assistência, bem como para prestar assistência de enfermagem de qualidade (Fugulin et al., 2011). $\mathrm{Na}$ atenção básica essa falta de pessoal é uma constante e diz respeito a todas as profissões. O preconizado pelo Ministério da Saúde, por meio da PNAB, não é adotado pelos municípios que aderiram ou não à ESF. A demanda excessiva de usuários está concatenada à falta de pessoal, pois faltam pessoas capazes e disponíveis para atender a população, sobrecarregando os profissionais atuantes no serviço de saúde.

Ainda no que diz respeito às condições de trabalho, o fator salário demonstrou impacto no nível de satisfação das enfermeiras, o que corrobora com um estudo realizado na Inglaterra, em que o incentivo financeiro exerce importante influência na qualidade da assistência prestada em atendimentos primários de saúde, pois as enfermeiras sentem-se mais reconhecidas no trabalho e exercem com mais prazer suas funções (Maisey et al., 2008).

Vale destacar que o salário na ESF é maior comparado com o salário na $\mathrm{ABT}$, devido à gratificação que os municípios repassam aos trabalhadores da ESF. Nesse contexto, as enfermeiras da ESF sentem-se satisfeitas com a remuneração que recebem, e isso se deve, exclusivamente, ao incentivo financeiro que os municípios repassam às equipes de saúde da família, o que não condiz com a realidade das enfermeiras da ABT. A justa remuneração contribui também para melhorar a qualidade de vida dos trabalhadores (Daubermann e Tonete, 2012).

Em ambos os modelos de atenção foi evidenciado o efeito negativo da influência político-partidária de cunho clientelista, o que as enfermeiras chamam de 'apadrinhamento político', na satisfação das enfermeiras e na assistência prestada aos usuários. Tal fato demonstra que os gestores municipais preocupam-se mais com os seus eleitores do que com a população como um todo, revelando o pouco preparo para a reorganização dos serviços de saúde de acordo com as diretrizes e princípios do SUS (Fernandes; Bertoldi e Barros, 2009).

Dentre os princípios do SUS, destacam-se aqui a universalidade e a equidade, em que todos os brasileiros devem ter acesso aos serviços e ações de saúde, cabendo priorizações com vistas a reduzir as desigualdades sociais, no sentido de justiça social. Portanto, o 'apadrinhamento político' segue em direção oposta aos princípios do SUS, ao garantir o atendimento aos usuários com desigualdade no sentido de atender a privilégios e não a necessidades desiguais. 


\section{Considerações finais}

Dentre os motivos de satisfação encontrados no trabalho das enfermeiras nos dois modelos assistenciais vigentes na atenção básica no Brasil, o 'trabalho em equipe' e o 'gostar do que faz' aparecem como fortes determinantes. Diante das adversidades, as enfermeiras procuram se firmar na vocação e no apoio mútuo nas equipes de trabalho, a fim de se fortalecerem no dia a dia.

A insatisfação no trabalho é significativamente influenciada pelas condições de trabalho, incluindo a escassez de recursos humanos e materiais. Destaca-se, ainda, a influência negativa da política partidária que se estabelece nas relações entre eleitores e eleitos, prejudicando o andamento das atividades das UBSs. Surpreende o fato de que essa influência se fez presente nos quatro municípios estudados.

Trabalhar na atenção básica gera, concomitantemente, motivos de satisfação e de insatisfação. Tais motivos aparentam não ter relação com o modelo assistencial, mas sim com as condições de trabalho, com algumas características próprias da profissão e com a subjetividade, no que diz respeito às percepções e expectativas das trabalhadoras.

A satisfação no trabalho é um tema complexo e se considerarmos a ESF como um novo modelo para a reorganização do trabalho na atenção básica, em que a enfermagem assume atuação essencial para a melhoria da assistência em saúde, cabe um aprofundamento dos estudos sobre essa temática.

\section{Colaboradores}

Elaine Cristina Novatzki Forte é a autora principal, responsável pela redação completa, e Denise Elvira Pires de Pires é responsável pelas revisões e orientações durante o estudo.

Resumen Se trata de una investigación cualitativa, con el objetivo de estudiar los motivos de satisfacción e insatisfacción en el trabajo, relatados por veinte enfermeras que actúan en dos modelos asistenciales utilizados en la atención básica en Brasil: el modelo tradicional y la Estrategia Salud de la Familia. Los datos se recolectaron entre marzo y mayo de 2013, por medio de triangulación, entrevistas y observación, organizados en el software Atlas.ti y se estudiaron en base al análisis de contenido. El estudio mostró 25 diferentes motivos de satisfacción y 23 diferentes motivos de insatisfacción en el trabajo. No fue significativa la diferencia entre los dos modelos de atención, indicando que éstos tienen mayor relación con la gestión municipal y con las condiciones de trabajo.

Palabras clave satisfacción en el trabajo; atención primaria de la salud; salud de la familia; papel de la enfermera. 


\section{Notas}

${ }^{1}$ Universidade Federal de Santa Catarina, Florianópolis, Santa Catarina, Brasil.

<elainecnforte@gmail.com>

Correspondência: Rua Jurerê Tradicional, 1.097, Jurerê, Florianópolis, Santa Catarina, Brasil, CEP 88053-750.

${ }^{2}$ Universidade Federal de Santa Catarina, Florianópolis, Santa Catarina, Brasil.

<piresdp@yahoo.com>

${ }^{3}$ Resultado parcial de dissertação de mestrado, intitulada A satisfação no trabalho de enfermeiros/as em dois modelos assistenciais na atenção básica no Brasil, de autoria de Elaine Cristina Novatzki Forte, apresentada no Programa de Pós-Graduação em Enfermagem, em setembro de 2013.

\section{Referências}

BARDIN, Laurence. Análise de conteúdo. Tradução de Luis Antero Reto e Augusto Pinheiro. Lisboa: Edições 70, 2009.

BRASIL. Ministério da Saúde. Secretaria de Atenção à Saúde. Departamento de Atenção Básica. Política Nacional de Atenção Básica. Brasília: Ministério da Saúde, 2011.

CORTELLA, Mário S. Qual é a tua obra? Rio de Janeiro: Vozes, 2009.

COELHO, Márcia O.; JORGE, Maria S. B. Tecnologia das relações como dispositivo do atendimento humanizado na atenção básica à saúde na perspectiva do acesso, do acolhimento e do vínculo. Ciência \& Saúde Coletiva, Rio de Janeiro, v. 14, supl. 1, p.1.523-1.531, 2009.

DAUBERMANN, Daiane C.; TONETE, Vera L. P. Qualidade de vida no trabalho do enfermeiro da Atenção Básica à Saúde. Acta Paulista de Enfermagem, São Paulo, v. 25, n. 2, p. 277-283, 2012. Disponível em: http://www.scielo.br/scielo. php? pid=S0103=21002012000200019-\&scriptsci_arttext. Acesso em: 23 jun. 2013.

DEJOURS, Christophe. A banalização da injustiça social. 7. ed. Rio de Janeiro: FGV Editora, 2011.
FERNANDES, Janielle S. et al. Qualidade de vida dos enfermeiros das equipes de saúde da família: a relação das variáveis sociodemográficas. Texto \& Contexto Enfermagem, Florianópolis, v.19, n. 3, jul.-set. 2010.

FERNANDES, Léia C. L.; BERTOLDI, Andréia D.; BARROS, Aluísio J. D. Utilização dos serviços de saúde pela população coberta pela Estratégia de Saúde da Família. Revista de Saúde Pública, São Paulo, v. 43, n. 4, p. 595-603, jun. 2009.

FINLAYSON, Mary P.; RAYMONT, Antony. Teamwork - general practitioners and practice nurses working together in New Zealand. Journal of Primary Health Care, Oslo, v. 4, n. 2, p. 150-155, jun. 2012.

FUGULIN, Fernanda M. T. et al. Custo da adequação quantitativa de profissionais de enfermagem em Unidade Neonatal. Revista da Escola de Enfermagem da USP, São Paulo, v. 45, número especial, p. 1.582-1.588, 2011.

GERNET, Isabelle; DEJOURS, Cristophe. Avaliação do trabalho e reconhecimento. In: BENDASSOLLI, Pedro F.; SOBOLL, Lis A. (orgs.). Clínicas do trabalho. São Paulo: Atlas, 2011. 
MAISEY, Susan et al. Effects of payment for performance in primary care: qualitative interview study. Journal of Health Services Research \& Policy, London, v. 13, n. 3, p. 133-139, 2008.

MARX, Karl. O capital. 8. ed. São Paulo: Difel, 1983

MERLO, Álvaro R. C.; MENDES, Ana M. B. Perspectivas do uso da psicodinâmica do trabalho no Brasil: teoria, pesquisa e ação. Cadernos de Psicologia Social do Trabalho, São Paulo, v. 12, n. 2, p. 141-156, 2009.

PEDUZZI, Marina et al. Trabalho em equipe na perspectiva da gerência de serviços de saúde: instrumentos para a construção da prática interprofissional. Physis: Revista de Saúde Coletiva, Rio de Janeiro, v. 21, n. 2, p. 629-646, 2011.

PIRES, Denise E. P. A enfermagem enquanto disciplina, profissão e trabalho. Revista Brasileira de Enfermagem, Brasília, v. 62, n. 5, p. 739-744, set.-out. 2009.
PIRES, Denise E. P. et al. Inovações tecnológicas no setor saúde e aumento das cargas de trabalho. Tempus Actas Saude Coletiva, Brasília, v. 6, n. 2, p. 45-59, 2012.

SANTANA, Leni L. et al. Cargas e desgastes de trabalho vivenciados entre trabalhadores de saúde em um hospital de ensino. Revista Gaúcha de Enfermagem, Porto Alegre, v. 34, n. 1, p, 64-70, 2013.

TRINDADE, Letícia L. et al. Estresse e síndrome de burnout entre trabalhadores da equipe de Saúde da Família. Acta Paulista de Enfermagem, São Paulo, v. 23, n. 5, p. 684-689, 2010.

TRINDADE, Letícia L.; PIRES, Denise E. P. Implicações dos modelos assistenciais da Atenção Básica nas cargas de trabalho dos profissionais de saúde. Texto \& Contexto Enfermagem, Florianópolis, v. 22, n. 1, p. 36-42, jan.-mar. 2013.

Recebido em 11/02/2014

Aprovado em 06/09/2016 